\title{
The Effectiveness of an Online Positive Psychology Intervention among Healthcare Professionals with Depression, Anxiety or Stress Symptoms and Burnout
}

\author{
Evangelia Alexiou, Aikaterini Kotsoni, Anastasios Stalikas \\ Panteion University of Social and Political Sciences, Athens, Greece \\ Email: evalexioy@gmail.com
}

How to cite this paper: Alexiou, E., Kotsoni, A., \& Stalikas, A. (2021). The Effectiveness of an Online Positive Psychology Intervention among Healthcare Professionals with Depression, Anxiety or Stress Symptoms and Burnout. Psychology, 12, 392-408.

https://doi.org/10.4236/psych.2021.123025

Received: February 10, 2021

Accepted: March 22, 2021

Published: March 25, 2021

Copyright $\odot 2021$ by author(s) and Scientific Research Publishing Inc. This work is licensed under the Creative Commons Attribution International License (CC BY 4.0).

http://creativecommons.org/licenses/by/4.0/

\begin{abstract}
This study aimed to test the effectiveness of an online positive psychology intervention among Greek healthcare professionals with depression, anxiety and/or stress symptoms and increased levels of burnout. The sample was consisted of 38 participants with mild, severe, or extremely severe symptoms of depression, anxiety and stress, and moderate or high levels of burnout, who were randomly assigned either to the intervention $(\mathrm{N}=19)$ or the active control group $(\mathrm{N}=19)$. Participants in the intervention group were introduced weekly to three positive psychology activities, whilst participants in the control group were given three placebo activities. All participants completed self-report questionnaires (Depression, Anxiety and Stress Scale, Maslach Burnout Inventory, Satisfaction with Life Scale, Positive and Negative Affect Scale) at the beginning and at the end of the three-week online intervention. The results indicated that the intervention group experienced statistically significant decreases in depression, anxiety, stress, and emotional exhaustion scores, as well as increases in satisfaction with life, compared to the control group which reported no changes. These findings suggest that such a positive psychology intervention could help healthcare professionals to manage their difficulties more effectively. Other clinical implications and recommendations for future research are also considered.
\end{abstract}

\section{Keywords}

Online Positive Psychology Intervention, Healthcare Professionals, Depression, Anxiety, Stress, Burnout, Well-Being 


\section{Introduction}

Healthcare professionals play a central and critical role in improving access and quality health care for the population (WHO, 2006). However, there is growing evidence that the prevalence of negative symptoms (depression, anxiety, stress) and burnout syndrome (emotional exhaustion, depersonalization, lack of personal accomplishment) among these professions is rapidly increasing worldwide. (Acker, 2012; Aiken, Sermeus, Van Den Heede, Sloane, Busse et al., 2012; Chan \& Huak, 2004; Lloyd \& King, 2004; Rachiotis, Kourousis, Kamilaraki, Symvoulakis, Dounias, \& Hadjichristodoulou, 2014). Providing health care can be a stressful job, as healthcare professionals are often responsible for human lives, and their actions-or lack of action-can have serious consequences for their patients (Sapountzi \& Lemonidou, 1994). They work under extremely demanding conditions and often face a variety of stressful situations, such as deadlines, high workloads, multiple roles and emotionally challenging moments. These factors can cause stress and negatively impact healthcare professionals' resilience, resulting in burnout (Aiken et al., 2012; Gonçalves, Fontes, Simães, \& Gomes, 2019; Rippstein-Leuenberger, Mauthner, Bryan Sexton, \& Schwendimann, 2017). Additionally, high levels of stress and burnout can have negative consequences for healthcare professionals, that is related to reduced attention and concentration (Skosnik, Chatterton, Swisher, \& Park, 2000), reduced work performance (Pakenham \& Stafford-Brown, 2012), less job satisfaction, physical and psychological complaints, higher rates of turnover and absenteeism (Cooper, Dewe, \& O’Driscoll, 2001), higher intention to quit their job (Acker, 2012), reduced service quality, and reduced patient satisfaction (Aiken et al., 2012).

Considering these facts, it becomes clear that healthcare professionals need support to manage stressful situations that are inherent in their work. Cultivation of well-being seems to be of great importance as it is related to reductions in mental illness, improved physical and mental health, sociability, use of effective conflict resolution skills and the intention to stay at work (Decker, Harris-Kojetin, \& Bercovitz, 2009; Hone, Jarden, Duncan, \& Schofield, 2015; Keyes, Dhingra, \& Simoes, 2010; Lyubomirsky, King, \& Diener, 2005a, 2005b). The current study examines whether an online intervention based on positive psychology can foster healthcare professionals' mental well-being, by reducing negative symptoms and burnout and increasing satisfaction with life and positive emotions.

Positive Psychology is a rapidly evolving branch of the science of psychology that promotes well-being and flourishing of people, improves their quality of life, and prevents pathologies that arise when life is barren and meaningless (Seligman \& Csikszentmihalyi, 2014). It is a science that promotes the study of conditions and processes that contribute to the optimal functioning of individuals, groups and institutions (Gable \& Haidt, 2005). Positive psychology interventions are defined as treatment methods or intentional activities that aim to cultivate positive emotions, behaviors and cognitions, as well as positive aspects of perso- 
nality (Sin \& Lyubomirsky, 2009). The effectiveness of positive psychology interventions is tested in single-component (one or two positive activities are used) and multi-component studies (three or more activities are used, Hendriks, 2018). Several meta-analyzes have shown that positive psychology interventions are highly effective in enhancing life satisfaction, positive effect, happiness and well-being among participants, while reducing negative effect and symptoms such as depression, anxiety and stress (Bolier, Haverman, Westerhof, Riper, Smit, \& Bohlmeijer, 2013; Chakhssi, Kraiss, Sommers-Spijkerman, \& Bohlmeijer, 2018; Hendriks, Schotanus-Dijkstra, Hassankhan, Graafsma, Bohlmeijer, \& de Jong, 2009).

Furthermore, positive psychology interventions can produce moderate to high improvements in healthcare professionals' well-being, burnout syndrome, and negative symptoms. Bolier, Ketelaar, Nieuwenhuijsen, Smeets, Gärtner \& Sluiter (2014), showed that healthcare professionals who participated in a positive psychology intervention reported improved mental health. Cheng, Tsui and Lam (2015), examined the effect of a positive psychology intervention compared to a placebo control, and results showed decreases in depression and stress for the healthcare professionals that took part in the experimental group. In a qualitative study, Rippstein-Leuenberger and colleagues (2017), tested the "three good things" positive intervention among healthcare professionals and it was found that after the intervention their well-being levels increased. In a similar research, Davidson, Graham, Montross-Thomas, Norcross \& Zerbi (2017) applied a positive intervention on healthcare professionals selected from four hospitals. 100\% of the participants answered that they found the intervention helpful and $84 \%$ stated that they would recommend it to others. Recently, Luo, Li, Plummer, Cross, Lam, Guo et al. (2019), evaluated the "three good things" intervention among nurses. After the intervention, the score of emotional exhaustion was significantly reduced in the participants who did the exercise compared to the control group. Mindfulness-Based Stress Reduction intervention in healthcare professionals has also been shown to be effective in increasing positive variables such as positive emotions and quality of life, and reducing negative ones, such as stress, anxiety and burnout (Galantino, Baime, Maguire Szapary, \& Farrar, 2005; Goodman \& Schorling, 2012; Shapiro, Astin, Bishop, \& Cordova, 2005; Shapiro, Brown, \& Biegel, 2007).

However, low participation rates were the most common limitation in these studies. Interventions that are less time-consuming are essential regarding that population. The flexibility provided by the online format of many positive psychology interventions makes it easier to apply to healthcare professionals who are characterized by a high workload (Bolier \& Abello, 2014; Sin \& Lyubomirsky, 2009), and that was why this form of administration was chosen in the present study.

\section{Present Study}

The aim of this study is to evaluate the effectiveness of a three-week online posi- 
tive psychology intervention among Greek healthcare professionals with depression, anxiety, or stress and burnout. The hypothesis is that compared to the control group, the participants in the intervention group will demonstrate decreased levels of 1) depression; 2) anxiety; 3) stress; 4) burnout; and 5) negative emotions; as well as increased levels of 6) positive emotions; and 7) satisfaction with life. These improvements will remain for one month following the completion of the intervention. The research questions of this study are as follows:

1) Is an online positive psychology intervention effective in reducing levels of depression, anxiety, or stress and negative emotions compared to the control group?

2) Is an online positive psychology intervention effective in reducing levels of emotional exhaustion, depersonalization, and/or increasing personal accomplishment compared to the control group?

3) Is an online positive psychology intervention effective in increasing levels of positive emotions and satisfaction with life compared to the control group?

4) Are the gains achieved present 1 month after the completion of the intervention?

\section{Method}

\subsection{Participants}

The participants were healthcare professionals (nurses, psychologists, social workers, and physiotherapists) who were either employed in public health institutions or worked privately, and were recruited from Athens, Greece via the internet. An advert was posted on social media sites related to health professions one month prior to the start of the intervention. Out of sixty-three people who completed the original questionnaire, thirty-eight participated in the study forming the intervention group (19) and the control group (19) (See Figure 1). The inclusion criteria were: 1) to work with their specialty and 2) the presence of mild to very severe symptoms of depression, anxiety, or stress as measured by the Depression, Anxiety, Stress Scale (DASS) and moderate or high symptoms of emotional exhaustion, depersonalization or lack of personal accomplishment by the Maslach Burnout Inventory (MBI). Participants who were attending another psychotherapeutic treatment were excluded from the study. 89.5\% (seventeen) of the participants in the intervention group were women and the mean age of the group was $33.9(\mathrm{SD}=8.69)$. For the control group, $89.5 \%$ were women with a mean age of $31.7(\mathrm{SD}=7.17)$. Table 1 outlines the demographic characteristics of the intervention and control group.

\subsection{Measures}

\subsubsection{Depression, Anxiety, Stress Scale (DASS-21)}

We used the Greek standardized version of the DASS-21 scale (Lovibond \& Lovibond, 1995; Lyrakos, Arvaniti, Smyrnioti, \& Kostopanagiotou, 2011) to measure symptoms of depression, anxiety and stress. The respondents are requested 


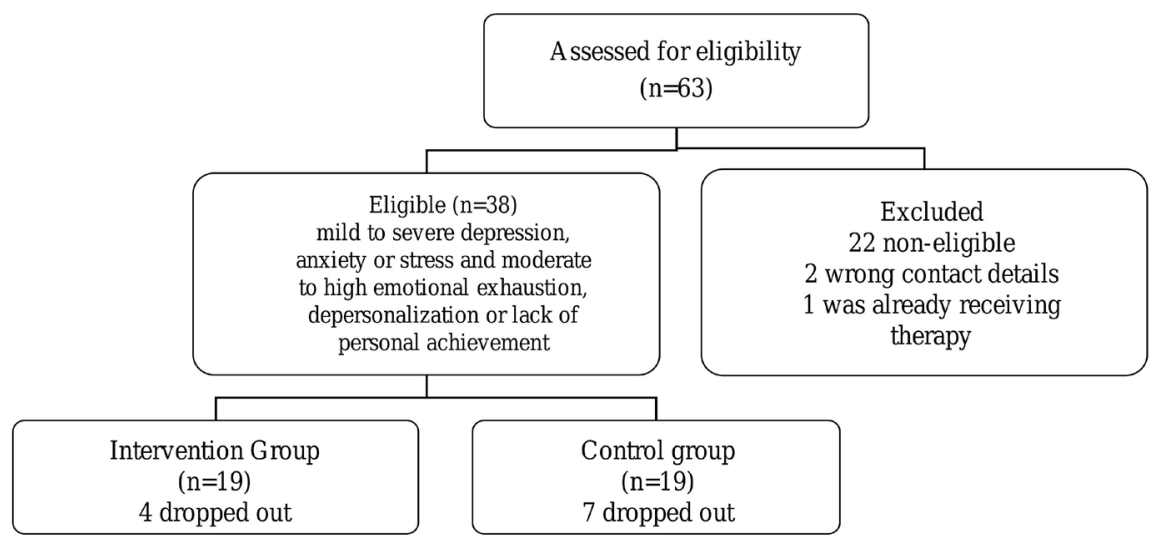

Figure 1. Selection process.

Table 1. Group demographics.

\begin{tabular}{|c|c|c|}
\hline & Intervention Group & Control Group \\
\hline \multicolumn{3}{|l|}{$\operatorname{Sex} \mathrm{n}(\%)$} \\
\hline Women & $17(89.5 \%)$ & $17(89.5 \%)$ \\
\hline Men & $2(11.5 \%)$ & $2(11.5 \%)$ \\
\hline Age M (SD) & $33.9(\mathrm{SD}=8.69)$ & $31.7(\mathrm{SD}=7.17)$ \\
\hline \multicolumn{3}{|l|}{ Marital Status n (\%) } \\
\hline Single & $10(52.6 \%)$ & $12(63.2 \%)$ \\
\hline Cohabit & $7(36.8 \%)$ & $7(36.8 \%)$ \\
\hline Divorced & $2(10.5 \%)$ & $0(0.0 \%)$ \\
\hline \multicolumn{3}{|l|}{ Education n (\%) } \\
\hline University Graduate & $12(63.2 \%)$ & $12(63.2 \%)$ \\
\hline MSc Degree & $7(36.8 \%)$ & $7(36.8 \%)$ \\
\hline \multicolumn{3}{|l|}{ Specialty n (\%) } \\
\hline Psychologists & $6(31.6 \%)$ & $9(47.4 \%)$ \\
\hline Social Workers & $6(31.6 \%)$ & $4(21.1 \%)$ \\
\hline Doctors & $1(5.3 \%)$ & $0(0.0 \%)$ \\
\hline Nurses & $2(10.5 \%)$ & $3(15.8 \%)$ \\
\hline Physiotherapists & $4(21.1 \%)$ & $3(15.8 \%)$ \\
\hline \multicolumn{3}{|l|}{ Sexual orientation $\mathbf{n}(\%)$} \\
\hline Heterosexual & $18(94.7 \%)$ & $17(89.5 \%)$ \\
\hline Homosexual & $0(0.0 \%)$ & $2(10.5 \%)$ \\
\hline Bisexual & $1(5.3 \%)$ & $0(0.0 \%)$ \\
\hline
\end{tabular}


to choose their answer on a 4-point self-report Likert scale ( 0 "did not apply to me at all" to 3 "applied to me very much or most of the time"). In our sample, the internal consistency was $\mathrm{a}=0.79$ for depression, $\mathrm{a}=0.76$ for anxiety $\& \mathrm{a}=$ 0.85 for stress.

\subsubsection{Maslach Burnout Inventory (MBI)}

The MBI (Maslach \& Jackson, 1986) consists of 22 items. Emotional exhaustion is measured by 9 items, depersonalization by 5 items, and personal accomplishment by 8 items. All items have a 7 -point Likert scale ranging from 0 "never experienced such a feeling" to 6 "experienced such feelings every day". Internal consistency reliability in the present study was $a=0.81$ for emotional exhaustion, $\mathrm{a}=0.88$ for depersonalization and $\mathrm{a}=0.64$ for lack of personal accomplishment.

\subsubsection{Scale of Positive and Negative Experience (SPANE)}

The SPANE comprises of 12 items with two dimensions, 6 items for positive and 6 items for negative feelings (Diener, Wirtz, Tov, Kim-Prieto, Choi, Oishi, \& Biswas-Diener, 2010). Respondents choose their answer using a modified Likert-type scale ranging from 1 (very rarely or never) to 5 (very often or always). The summed score can range from 6 to 30 for each dimension and the two scores can be combined by subtracting the negative score from the positive score, and the resulting scores can range from -24 to 24 . The scale has been validated in the Greek population by Kyriazos, Stalikas, Prassa, \& Yotsidi (2018). In this study, the internal consistency was $\mathrm{a}=0.87$ for the positive experience and $\mathrm{a}=0.82$ for the negative experience.

\subsubsection{Satisfaction with Life Scale (SWLS)}

Diener's Satisfaction with Life Scale was provided in its Greek version (Diener, Emmons, Larsen, \& Griffin, 1985; Stalikas \& Lakioti, 2012). It consists of 5 items that measure global life satisfaction and people choose their answer using a 7 -point Likert scale (1 “strongly disagree" to 7 "strongly agree"). The internal consistency in the present study was $\mathrm{a}=0.88$.

\subsection{Procedure}

All participants were informed on the purpose of the study and completed a consent form. Firstly, they answered a battery of questionnaires and those who were eligible to participate in the study, completed the same questionnaires at the beginning, at the end, and one month after the intervention. All questionnaires were distributed online. The members of the control group were offered the opportunity to attend the intervention after the completion of the study. The intervention ran for 3 weeks.

The content of the current intervention was based on evidence-based positive psychology activities, which have been previously applied on clinical or non-clinical population and healthcare professionals, and have been found to be 
effective in reducing symptoms of depression, anxiety, or stress, and burnout, as well as improving wellbeing (Curry, Rowland, Van Lissa, Zlotowitz, McAlaney, \& Whitehouse, 2018; Enrique, Bretón-López, Molinari, Baños, \& Botella, 2017; Loveday, Lovell, \& Jones, 2018; Luo et al., 2019; Rippstein-Leuenberger et al., 2017; Seligman, Steen, Park, \& Peterson, 2005). They are covered by three key topics of well-being: 1) gratitude, 2) kindness, and 3) optimism. The placebo control exercises were derived from previous randomized controlled trials and have been found to have a neutral effect on the participants of the studies (Giannopoulos \& Vella-Brodrick, 2011; Seligman et al., 2005; Trew \& Alden, 2015).

At the beginning of each week participants received an e-mail with instructions tailored to each exercise, and in the middle of the week they received a reminder e-mail. Participants in the intervention group were asked to complete three positive psychology activities, whereas participants in the control group were asked to complete three placebo exercises.

\subsubsection{Positive Psychology Activities}

Three good things. In the first week, participants were asked to write down three things that went well each day. They were also asked to provide a causal explanation for each good thing (Seligman et al., 2005).

Acts of kindness. In the second week, participants were asked to perform five acts of kindness within the week, all in one day. Such actions have been described as behaviors that benefit other people or make them happy, and usually have some cost to themselves (Lyubomirsky, Sheldon, \& Schkade, 2005).

The best possible self. In the third week, participants were asked to imagine their best selves in the future having accomplished all their dreams. They were instructed to choose a different area of their lives each day for a week (e.g. career, family life, hobbies or personal interests, social life, physical health, mental health, community involvement) and then write down their thoughts and what they needed to do to make it happen in reality (Sheldon \& Lyubomirsky, 2006).

\subsubsection{Placebo Exercises}

Placebo control exercise: Daily events. In the first week, participants were instructed to write down three daily events every night for 1 week (Giannopoulos \& Vella-Brodrick, 2011).

Placebo control exercise: Early memories. In the second week, participants were asked to write about their early memories every night for 1 week (Seligman et al., 2005).

Placebo control exercise: Life events. Participants were asked to pay attention and then record at least 3 events that occurred each day (Trew \& Alden, 2015).

\section{Results}

The data were examined for the normality of their distribution, to decide whether parametric or non-parametric tests will be used. All data followed the 
normal distribution. At the baseline there were no statistically significant differences between the control and the intervention group regarding their sociodemographic characteristics or variable measures therefore the two groups can be considered equivalent (Table $1 \&$ Table 2). For the analysis of the data the program SPSS Statistics version 25 was used.

To answer the first, second and third research questions that are whether the intervention group showed statistically significant differences compared to the control group, a series of two-tailed paired samples t-tests were employed to examine pre and post changes for each group. Answering the first question the results showed that the intervention group demonstrated a statistically significant difference in the scores of depression $(\mathrm{t}=3.410, p=0.004)$, anxiety $(\mathrm{t}=$ $3.150, p=0.007)$, and stress $(\mathrm{t}=3.213, p=0.006)$, but not in the scores of negative emotions $(\mathrm{t}=1.853, p=0.084)$ before and after the intervention. No statistically significant difference was found in any of the post intervention outcome of the control group: depression $(\mathrm{t}=-0.902, p=0.386)$, anxiety $(\mathrm{t}=1.173, p=$ $0.266)$, stress $(\mathrm{t}=1.514, p=0.158)$, and negative emotions $(\mathrm{t}=-1.363, p=$ 0.200 ).

Similarly, to test the second hypothesis, paired sample t-tests were used for each group. For the intervention group, there was a statistically significant decrease in the levels of emotional exhaustion $(\mathrm{t}=2.433, p=0.028)$, but no differences observed in depersonalization $(\mathrm{t}=1.235, p=0.236)$, and personal accomplishment scores $(\mathrm{t}=-0.823, p=0.423)$. No statistically significant changes were observed for the control group: emotional exhaustion $(\mathrm{t}=1.242, p=0.240)$, depersonalization $(\mathrm{t}=0.650, p=0.529)$, and personal accomplishment $(\mathrm{t}=-0.740$, $p=0.475)$.

Table 2. Mean scores for outcome measures by group for pre-group (Pre) and post-group (Post).

\begin{tabular}{ccccc}
\hline & \multicolumn{2}{c}{ Intervention Group } & \multicolumn{2}{c}{ Control Group } \\
\cline { 2 - 5 } & Pre & Post & Pre & Post \\
\cline { 2 - 5 } & $\mathrm{M}(\mathrm{SD})$ & $\mathrm{M}(\mathrm{SD})$ & $\mathrm{M}(\mathrm{SD})$ & $\mathrm{M}(\mathrm{SD})$ \\
\hline Depression & $10.37(4.17)$ & $6.94(4.21)$ & $6.83(3.32)$ & $8.50(5.63)$ \\
Anxiety & $8.38(4.25)$ & $3.56(2.98)$ & $5.75(3.36)$ & $4.42(5.64)$ \\
Stress & $11.69(3.75)$ & $6.06(4.13)$ & $7.17(3.56)$ & $5.33(3.47)$ \\
Emotional Exhaustion & $28.19(9.07)$ & $23.44(9.79)$ & $19.75(8.90)$ & $17.78(9.99)$ \\
Depersonalization & $13.13(6.42)$ & $11.50(4.25)$ & $8.25(5.73)$ & $7.58(4.58)$ \\
Personal Accomplishment & $27.75(5.19)$ & $28.75(4.87)$ & $33.17(5.34)$ & $34.42(6.96)$ \\
Satisfaction with Life & $19.69(7.19)$ & $26.75(3.23)$ & $22.27(3.92)$ & $23.08(3.84)$ \\
Positive Emotions & $16.81(4.13)$ & $17.69(3.61)$ & $19.92(3.91)$ & $21.50(4.46)$ \\
Negative Emotions & $20.56(2.94)$ & $18.44(3.46)$ & $16.50 \quad(4.31)$ & $19.75(7.94)$ \\
\hline
\end{tabular}


For the third research question, two-tailed paired sample t-tests revealed that there was a statistically significant increase in life satisfaction $(\mathrm{t}=-3.590, p=$ $0.003)$, but not in positive emotions scores $(t=-0.687, p=0.503)$ for the intervention group. There were no statistically significant differences either in life satisfaction $(\mathrm{t}=-0.928, p=0.374)$, or in positive emotions scores $(\mathrm{t}=-1.144, p=$ 0.277 ) for the control group.

To test the fourth research question, "Are the gains achieved present 1 month after the completion of the intervention", a series of t-tests comparing the post outcome measures with the 1-month follow up were conducted for the intervention group. According to the findings, there was no significant difference for depression $(\mathrm{t}=2.011, p=0.064)$, anxiety $(\mathrm{t}=0.712, p=0.488)$, stress $(\mathrm{t}=0.609, p$ $=0.552)$, emotional exhaustion $(\mathrm{t}=0.485, p=0.635)$, and satisfaction with life $(\mathrm{t}$ $=1.513, p=0.153)$. These results demonstrate that the variables levels in which participants showed improvement after the positive psychology intervention remained at the same levels 1 month after the completion of the intervention.

The graph below indicates the changes in depression, anxiety, stress, and emotional exhaustion variables for the intervention group (Figure 2). The significant increase in satisfaction with life is illustrated in Figure 3.

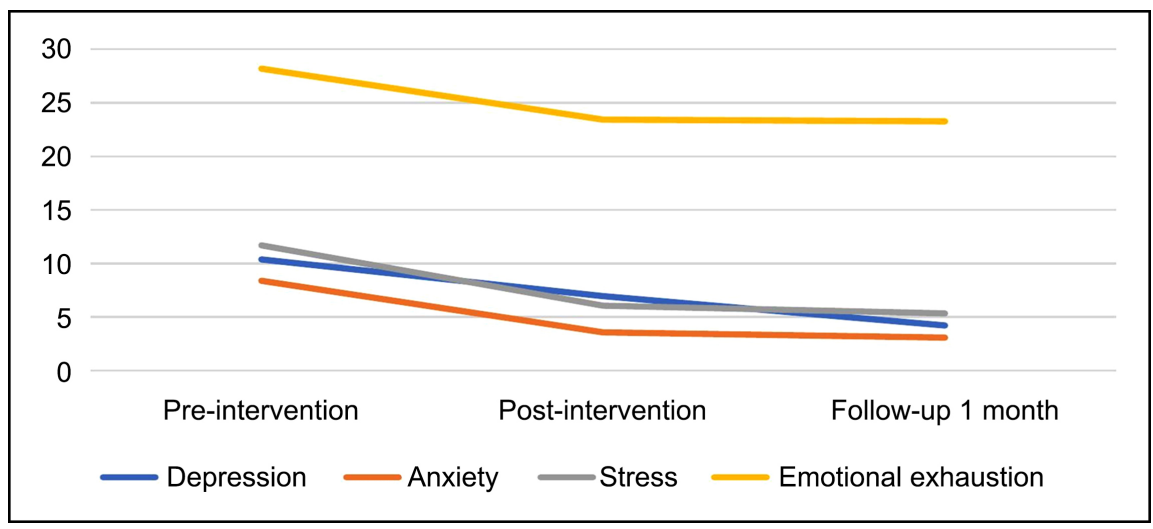

Figure 2. Depression, anxiety, stress, and emotional exhaustion pre, post and 1 month after the positive psychology intervention.

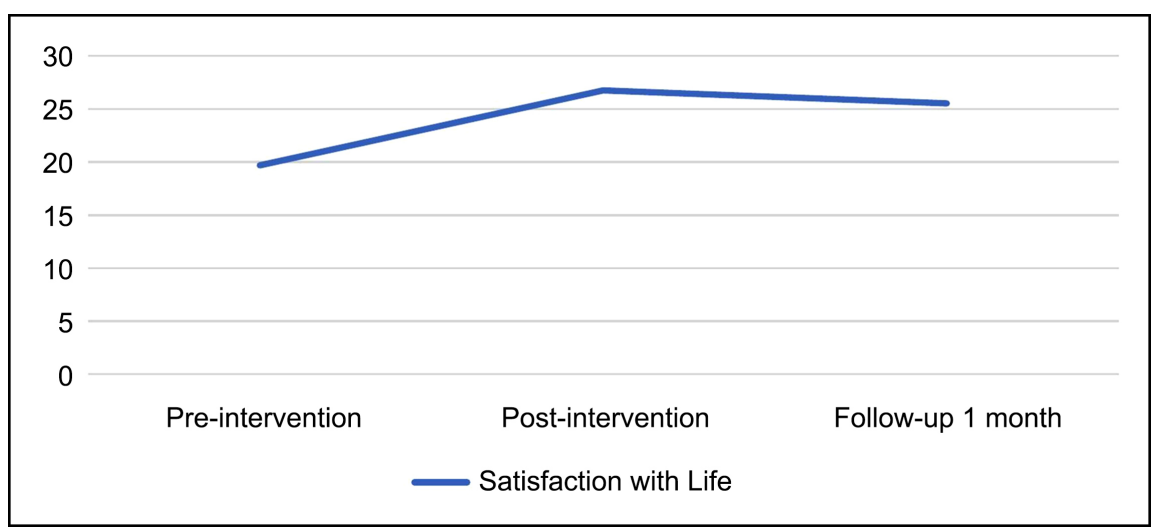

Figure 3. Satisfaction with life pre, post and 1 month after the positive psychology intervention. 


\section{Discussion}

To our knowledge, the current study was the first to evaluate the effectiveness of an online positive psychology intervention among Greek healthcare professionals with depression, anxiety, or stress and burnout.

The hypotheses of our study were partially confirmed. The participants of the positive psychology intervention reported statistically significant lower levels of depression, anxiety, stress, and emotional exhaustion after the completion of the intervention. There was also a significant increase in their levels of satisfaction with life. All changes were maintained one month after the completion of the intervention. The control group, that received placebo exercises, did not demonstrate any statistically significant differences. Since both groups were similar in other characteristics before the intervention, we can assume that the changes observed in the intervention group are due to the positive psychology intervention. These findings enrich the existing literature regarding the effectiveness of positive psychology interventions among healthcare professionals (Bolier et al., 2014; Cheng et al., 2015; Davidson et al., 2017; Luo et al., 2019; Rippstein-Leuenberger et al., 2017).

In line with our expectations, the results of this study indicated that this positive psychology intervention led to an important decrease in all three dimensions of negative emotions (depression, anxiety, stress). As other studies have shown, the "three good things", "acts of kindness" and "the best possible self" interventions, reduce participants' negative symptoms such as stress, depression (Cheng et al., 2015; Enrique et al., 2017; Paviglianiti \& Irwin, 2017; Seligman et al., 2005) and anxiety (Kerr, O’Donovan, \& Pepping, 2014).

The MBI results detected changes in the emotional exhaustion dimension of burnout but not in the personalization and personal accomplishment dimensions. This finding seems to be consistent with the results of a previous study, where the "three good things" intervention induced a decrease only in the dimension of emotional exhaustion among nurses with burnout (Luo et al., 2019). According to the burnout model of Taris, Le Blanc, Schaufeli, \& Schreurs (2005), emotional exhaustion is the key dimension and the first stage of burnout. An individual's reduced emotional exhaustion, can lead to a reduction in depersonalization, which in turn increases personal accomplishment. Thus, we can assume that the decrease of emotional exhaustion observed in the intervention group, may affect the other two dimensions in the long run.

Furthermore, the results showed that this positive psychology intervention led to a significant increase in life satisfaction levels. As has been observed in previous studies, the three positive psychology activities that were delivered to the participants of the intervention group, can positively change the way one evaluates life (Buchanan \& Bardi, 2010; Boehm, Lyubomirsky, \& Sheldon, 2011; Manthey, Vehreschild, \& Renner, 2014). That finding has significant value as it has been found that among the most effective strategies that help healthcare professionals deal with stress are the positive evaluations of everyday life events 
(Koinis, Giannou, Drantaki, Angelaina, Stratou, \& Saridi, 2015).

No changes were detected in SPANE variable. As it seems, this intervention had an impact on the cognitive but not on the emotional component of well-being (Mitchell, Stanimirovic, Klein, \& Vella-Brodrick, 2009). Two possible conditions are considered to explain this phenomenon. Diener, Suh, Lucas, and Smith (1999) introduced a definition of subjective well-being, arguing that it consists of three different components: high life satisfaction (cognitive factor), frequent positive emotion, and rare negative emotion (emotional factor). They also stressed that these factors are independent of each other and should be measured separately. This means that a person may demonstrate high levels of life satisfaction, and at the same time he may report low levels of positive emotion, and/or high levels of negative emotion, and vice versa. Alternatively, the fact that the majority of participants in the present study showed moderate to high symptoms of depression, anxiety or stress, may have had an impact on this result. According to Kerr et al. (2014), such positive interventions may require more time to cause changes in the levels of positive and negative emotions, if they are delivered to clinical population.

As we expected, all changes were maintained one month after the completion of the intervention. Previous research is consistent with this finding as it has been shown that positive interventions are a very useful tool for improving mental health and their effect can be longlasting (Cohn \& Frederickson, 2010), as it can be a product of learning (Seligman et al., 2005).

\subsection{Limitations and Future Directions}

This study has a few limitations that offer important directions for future research. First, it should be noted that the present study was performed during the period of lockdown due to the COVID-19 virus pandemic. This may have affected the results to some extent, so the study should be repeated in a neutral period, to examine whether specific variables, such as high participation rates and compliance with the activities would remain at the same levels.

Also, the sample of the study was small and consisted mainly of women. Thus, our results might not be generalizable to other healthcare professionals with more diverse demographics. Future studies should aim to recruit a larger sample of to explore whether the same results will be extracted.

Another important factor to consider is that due to time constraints, we were unable to perform another follow-up measure. Future studies could include follow-up measures three or six months later to ensure that the gains are maintained and potentially detect significant differences in other measures, such as depersonalization, personal accomplishments, and positive or negative emotions, as it may take longer for changes to occur in these variables.

Finally, although the present study was conducted using self-report questionnaires, it would be interesting for future studies to use a combination of quantitative and qualitative data in order to eliminate the common method variance 
which may have impacted our results (Podsakoff, MacKenzie, Lee, \& Podsakoff, 2003), and examine which are the components of positive interventions that contribute to mental health gains.

Future research would do well to implement this online positive psychology intervention to similar vulnerable population that has been shown to suffer from burnout symptoms, such as teachers or employees of large organizations (Hakanen, Bakker, \& Schaufeli, 2006. Maslach, Schaufeli, \& Leiter, 2001). It could also be used in specific clinical population, like people with anxiety disorders, depression, etc., as it has been shown that such interventions may be useful before treatment because they reduce the negative impact of waiting for treatment (Kerr et al., 2014).

\subsection{Implications}

Overall, the results of the present study show that this online positive psychology intervention has significant benefits for this special population. From a theoretical perspective, scientific knowledge related to the effectiveness of positive psychology interventions among healthcare professionals is broadened. From a clinical perspective, this brief online positive psychology intervention offers opportunities for the large and growing numbers of healthcare professionals to enhance well-being and alleviate negative symptoms and burnout, by way of self-care. Immersing such a mental health program within a structural workplace strategy may help to contribute to the success of this intervention. It could be implemented in a broad range of healthcare settings, as it constitutes a less time consuming and more cost-effective method to develop psychological resilience and empower their emotional and cognitive skills. When healthcare professionals feel that their work enviroment provides support and nurtures their psychological needs, they will be more likely to function well and invest their time and energy in their patients (Bakker, 2011). Finally, during a crisis period, like the Covid-19 pandemic, the dissemination of such an intervention on as many healthcare professionals as possible, combined with appropriate surveillance and encouragement, could be beneficial on public mental health as a whole.

\section{Conflicts of Interest}

The authors declare no conflicts of interest regarding the publication of this paper.

\section{References}

Acker, G. M. (2012). Burnout among Mental Health Care Providers. Journal of Social Work, 12, 475-490. https://doi.org/10.1177/1468017310392418

Aiken, L. H., Sermeus, W., Van Den Heede, K., Sloane, D. M., Busse, R., McKee, M., Bruyneel, L., Rafferty, A. M., Griffiths, P., Moreno-Casbas, M. T., Tishelman, C., Scott, A., Brzostek, T., Kinnunen, J., Schwendimann, R., Heinen, M., Zikos, D., Sjetne, I. S., Smith, H. L., \& Kutney-Lee, A. (2012). Patient Safety, Satisfaction, and Quality of Hospital Care: Cross Sectional Surveys of Nurses and Patients in 12 Countries in Europe 
and the United States. British Medical Journal (Online), 344, e1717. https://doi.org/10.1136/bmj.e1717

Bakker, A. B. (2011). An Evidence-Based Model of Work Engagement. Current Directions in Psychological Science, 20, 265-269. https://doi.org/10.1177/0963721411414534

Boehm, J. K., Lyubomirsky, S., \& Sheldon, K. M. (2011). A Longitudinal Experimental Study Comparing the Effectiveness of Happiness-Enhancing Strategies in Anglo Americans and Asian Americans. Cognition \& Emotion, 25, 1263-1272. https://doi.org/10.1080/02699931.2010.541227

Bolier, L., \& Abello, K. M. (2014). Online Positive Psychological Interventions: State of the Art and Future Directions. In A. C. Parks, \& S. M. Schueller (Eds.), The Wiley Blackwell Handbook of Positive Pscyhological Interventions (pp. 286-309). Hoboken, NJ: John Wiley \& Sons, Ltd. https://doi.org/10.1002/9781118315927.ch16

Bolier, L., Haverman, M., Westerhof, G. J., Riper, H., Smit, F., \& Bohlmeijer, E. (2013). Positive Psychology Interventions: A Meta-Analysis of Randomized Controlled Studies. BMC Public Health, 13, Article No. 119.

https://doi.org/10.1186/1471-2458-13-119

Bolier, L., Ketelaar, S. M., Nieuwenhuijsen, K., Smeets, O., Gärtner, F. R., \& Sluiter, J. K. (2014). Workplace Mental Health Promotion Online to Enhance Well-Being of Nurses and Allied Health Professionals: A Cluster-Randomized Controlled Trial. Internet Interventions, 1, 196-204. https://doi.org/10.1016/j.invent.2014.10.002

Buchanan, K. E., \& Bardi, A. (2010). Acts of Kindness and Acts of Novelty Affect Life Satisfaction. The Journal of Social Psychology, 150, 235-237.

https://doi.org/10.1080/00224540903365554

Chakhssi, F., Kraiss, J. T., Sommers-Spijkerman, M., \& Bohlmeijer, E. T. (2018). The Effect of Positive Psychology Interventions on Well-Being and Distress in Clinical Samples with Psychiatric or Somatic Disorders: A Systematic Review and Meta-Analysis. BMC Psychiatry, 18, Article No. 211. https://doi.org/10.1186/s12888-018-1739-2

Chan, A. O. M., \& Huak, C. Y. (2004). Influence of Work Environment on Emotional Health in a Health Care Setting. Occupational Medicine (Oxford, England), 54, 207-212. https://doi.org/10.1093/occmed/kqh062

Cheng, S.-T., Tsui, P. K., \& Lam, J. H. M. (2015). Improving Mental Health in Health Care Practitioners: Randomized Controlled Trial of a Gratitude Intervention. Journal of Consulting and Clinical Psychology, 83, 177-186. https://doi.org/10.1037/a0037895

Cohn, M. A., \& Fredrickson, B. L. (2010). In Search of Durable Positive Psychology Interventions: Predictors and Consequences of Long-Term Positive Behavior Change. The Journal of Positive Psychology, 5, 355-366. https://doi.org/10.1080/17439760.2010.508883

Cooper, C. L., Dewe, P. J., \& O’Driscoll, M. P. (2001). Foundations for Organizational Science. Organizational Stress: A Review and Critique of Theory, Research and Applications. Thousand Oaks, CA: Sage Publications, Inc.

Curry, O. S., Rowland, L. A., Van Lissa, C. J., Zlotowitz, S., McAlaney, J., \& Whitehouse, H. (2018). Happy to Help? A Systematic Review and Meta-Analysis of the Effects of Performing Acts of Kindness on the Well-Being of the Actor. Journal of Experimental Social Psychology, 76, 320-329. https://doi.org/10.1016/j.jesp.2018.02.014

Davidson, J. E., Graham, P., Montross-Thomas, L., Norcross, W., \& Zerbi, G. (2017). Code Lavender: Cultivating Intentional Acts of Kindness in Response to Stressful Work Situations. EXPLORE, 13, 181-185. https://doi.org/10.1016/j.explore.2017.02.005

Decker, F. H., Harris-Kojetin, L. D., \& Bercovitz, A. (2009). Intrinsic Job Satisfaction, Overall Satisfaction, and Intention to Leave the Job among Nursing Assistants in 
Nursing Homes. The Gerontologist, 49, 596-610.

https://doi.org/10.1093/geront/gnp051

Diener, E., Emmons, R. A., Larsen, R. J., \& Griffin, S. (1985). The Satisfaction with Life Scale. Journal of Personality Assessment, 49, 71-75. https://doi.org/10.1207/s15327752jpa4901_13

Diener, E., Suh, E. M., Lucas, R. E., \& Smith, H. L. (1999). Subjective Well-Being: Three Decades of Progress. Psychological Bulletin, 125, 276-302. https://doi.org/10.1037/0033-2909.125.2.276

Diener, E., Wirtz, D., Tov, W., Kim-Prieto, C., Choi, D., Oishi, S., \& Biswas-Diener, R. (2010). New Wellbeing Measures: Short Scales to Assess Flourishing and Positive and Negative Feelings. Social Indicators Research, 97, 143-156. https://doi.org/10.1007/s11205-009-9493-y

Enrique, Á., Bretón-López, J., Molinari, G., Baños, R. M., \& Botella, C. (2017). Efficacy of an Adaptation of the Best Possible Self Intervention Implemented through Positive Technology: A Randomized Control Trial. Applied Research in Quality of Life, 13, 671-689. https://doi.org/10.1007/s11482-017-9552-5

Gable, S. L., \& Haidt, J. (2005). What (and Why) Is Positive Psychology? Review of General Psychology, 9, 103-110. https://doi.org/10.1037/1089-2680.9.2.103

Galantino, M. L., Baime, M., Maguire, M., Szapary, P. O., \& Farrar, J. T. (2005). Association of Psychological and Physiological Measures of Stress in Health-Care Professionals during an 8-Week Mindfulness Meditation Program: Mindfulness in Practice. Stress \& Health, 21, 255-261. https://doi.org/10.1002/smi.1062

Giannopoulos, V. L., \& Vella-Brodrick, D. A. (2011). Effects of Positive Interventions and Orientations to Happiness on Subjective Well-Being. The Journal of Positive Psychology, 6, 95-105. https://doi.org/10.1080/17439760.2010.545428

Gonçalves, A., Fontes, L., Simães, C., \& Gomes, A. R. (2019). Stress and Burnout in Health Professionals. In P. Arezes et al. (Eds.), Occupational and Environmental Safety and Health (pp. 563-571). Cham: Springer. http://hdl.handle.net/1822/59328

https://doi.org/10.1007/978-3-030-14730-3_60

Goodman, M. J., \& Schorling, J. B. (2012). A Mindfulness Course Decreases Burnout and Improves Well-Being among Healthcare Providers. The International Journal of Psychiatry in Medicine, 43, 119-128. https://doi.org/10.2190/PM.43.2.b

Hakanen, J. J., Bakker, A. B., \& Schaufeli, W. B. (2006). Burnout and Work Engagement among Teachers. Journal of School Psychology, 43, 495-513. https://doi.org/10.1016/j.jsp.2005.11.001

Hendriks, T. (2018). Positive Psychology Interventions in a Multi-Ethnic and Cross Cultural Context. Doctoral Dissertation, Amsterdam: Universiteit van Amsterdam.

Hendriks, T., Schotanus-Dijkstra, M., Hassankhan, A., Graafsma, T., Bohlmeijer, E., \& de Jong, J. (2018). The Efficacy of Positive Psychology Interventions from Non-Western Countries: A Systematic Review and Meta-Analysis. International Journal of Wellbeing, 8, 71-98. https://doi.org/10.5502/ijw.v8i1.711

Hone, L. C., Jarden, A., Duncan, S., \& Schofield, G. M. (2015). Flourishing in New Zealand Workers. Journal of Occupational and Environmental Medicine, 57, 973-983. https://doi.org/10.1097/JOM.0000000000000508

Kerr, S. L., O’Donovan, A., \& Pepping, C. A. (2014). Can Gratitude and Kindness Interventions Enhance Well-Being in a Clinical Sample? Journal of Happiness Studies, 16, 17-36. https://doi.org/10.1007/s10902-013-9492-1

Keyes, C. L. M., Dhingra, S. S., \& Simoes, E. J. (2010). Change in Level of Positive Mental 
Health as a Predictor of Future Risk of Mental Illness. American Journal of Public Health, 100, 2366-2371. https://doi.org/10.2105/AJPH.2010.192245

Koinis, A., Giannou, V., Drantaki, V., Angelaina, S., Stratou, E., \& Saridi, M. (2015). The Impact of Healthcare Workers Job Environment on Their Mental-Emotional Health. Coping Strategies: The Case of a Local General Hospital. Health Psychology Research, 3. https://doi.org/10.4081/hpr.2015.1984

Kyriazos, T., Stalikas, A., Prassa, K., \& Yotsidi, V. (2018). A 3-Faced Construct Validation and a Bifactor Subjective Well-Being Model Using the Scale of Positive and Negative Experience, Greek Version. Psychology, 9, 1143-1175. https://doi.org/10.4236/psych.2018.95071

Lloyd, C., \& King, R. (2004). A Survey of Burnout among Australian Mental Health Occupational Therapists and Social Workers. Social Psychiatry and Psychiatric Epidemiology, 39, 752-757. https://doi.org/10.1007/s00127-004-0808-7

Loveday, P. M., Lovell, G. P., \& Jones, C. M. (2018). The Best Possible Selves Intervention: A Review of the Literature to Evaluate Efficacy and Guide Future Research. Journal of Happiness Studies, 19, 607-628. https://doi.org/10.1007/s10902-016-9824-Z

Lovibond, P. F., \& Lovibond, S. H. (1995). The Structure of Negative Emotional States: Comparison of the Depression Anxiety Stress Scales (DASS) with the Beck Depression and Anxiety Inventories. Behaviour Research and Therapy, 33, 335-343.

Luo, Y., Li, H., Plummer, V., Cross, W. M., Lam, L., Guo, Y. et al. (2019). An Evaluation of a Positive Psychological Intervention to Reduce Burnout among Nurses. Archives of Psychiatric Nursing, 33, 186-191. https://doi.org/10.1016/j.apnu.2019.08.004

Lyrakos, G. N., Arvaniti, C., Smyrnioti, M., \& Kostopanagiotou, G. (2011). P03-561Translation and Validation Study of the Depression Anxiety Stress Scale in the Greek General Population and in a Psychiatric Patient's Sample. European Psychiatry, 26, 1731. https://doi.org/10.1016/S0924-9338(11)73435-6

Lyubomirsky, S., King, L., \& Diener, E. (2005a). The Benefits of Frequent Positive Affect: Does Happiness Lead to Success? Psychological Bulletin, 131, 803-855.

https://doi.org/10.1037/0033-2909.131.6.803

Lyubomirsky, S., King, L., \& Diener, E. (2005b). The Benefits of Frequent Positive Affect: Does Happiness Lead to Success? Psychological Bulletin, 131, 803-855. https://doi.org/10.1037/0033-2909.131.6.803

Lyubomirsky, S., Sheldon, K. M., \& Schkade, D. (2005). Pursuing Happiness: The Architecture of Sustainable Change. Review of General Psychology, 9, 111-131. https://doi.org/10.1037/1089-2680.9.2.111

Manthey, L., Vehreschild, V., \& Renner, K.-H. (2014). Effectiveness of Two Cognitive Interventions Promoting Happiness with Video-Based Online Instructions. Journal of Happiness Studies, 17, 319-339. https://doi.org/10.1007/s10902-014-9596-2

Maslach, C., \& Jackson, S. E. (1986). Maslach Burnout Inventory Manual (2nd ed.). Palo Alto, CA: Consulting Psychologists Press.

Maslach, C., Schaufeli, W. B., \& Leiter, M. P. (2001). Job Burnout. Annual Review of Psychology, 52, 397-422. https://doi.org/10.1146/annurev.psych.52.1.397

Mitchell, J., Stanimirovic, R., Klein, B., \& Vella-Brodrick, D. (2009). A Randomised Controlled Trial of a Self-Guided Internet Intervention Promoting Well-Being. Computers in Human Behavior, 25, 749-760. https://doi.org/10.1016/j.chb.2009.02.003

Pakenham, K. I., \& Stafford-Brown, J. (2012). Stress in Clinical Psychology Trainees: A Review of Current Research and Future Directions. Australian Psychologist, 47, 147-155. https://doi.org/10.1111/j.1742-9544.2012.00070.x 
Paviglianiti, N. C. \& Irwin, J. D. (2017). Students' Experiences of a Voluntary Random Acts of Kindness Health Promotion Project. Youth Engagement in Health Promotion, 1, 1-23. http://works.bepress.com/jenniferirwin/171/

Podsakoff, P. M., MacKenzie, S. B., Lee, J. Y., \& Podsakoff, N. P. (2003). Common Method Biases in Behavioral Research: A Critical Review of the Literature and Recommended Remedies. Journal of Applied Psychology, 88, 879-903.

https://doi.org/10.1037/0021-9010.88.5.879

Rachiotis, G., Kourousis, C., Kamilaraki, M., Symvoulakis, E. K., Dounias, G., \& Hadjichristodoulou, C. (2014). Medical Supplies Shortages and Burnout among Greek Health Care Workers during Economic Crisis: A Pilot Study. International Journal of Medical Sciences, 11, 442-447. https://www.medsci.org/v11p0442.htm https://doi.org/10.7150/ijms.7933

Rippstein-Leuenberger, K., Mauthner, O., Bryan Sexton, J., \& Schwendimann, R. (2017). A Qualitative Analysis of the Three Good Things Intervention in Healthcare Workers. BMJ Open, 7, e015826. https://doi.org/10.1136/bmjopen-2017-015826

Sapountzi, D., \& Lemonidou, C. (1994). Nursing in Greece. Developments and Prospects. Athens: Academy of Health Professions.

Seligman, M. E. P., \& Csikszentmihalyi, M. (2014). Positive Psychology: An Introduction. In Flow and the Foundations of Positive Psychology (pp. 279-298). Dordrecht: Springer. https://doi.org/10.1007/978-94-017-9088-8_18

Seligman, M. E. P., Steen, T. A., Park, N., \& Peterson, C. (2005). Positive Psychology Progress: Empirical Validation of Interventions. American Psychologist, 60, 410-421. https://doi.org/10.1037/0003-066X.60.5.410

Shapiro, S. L., Astin, J. A., Bishop, S. R., \& Cordova, M. (2005). Mindfulness-Based Stress Reduction for Health Care Professionals: Results from a Randomized Trial. International Journal of Stress Management, 12, 164-176.

https://doi.org/10.1037/1072-5245.12.2.164

Shapiro, S. L., Brown, K. W., \& Biegel, G. M. (2007). Teaching Self-Care to Caregivers: Effects of Mindfulness-Based Stress Reduction on the Mental Health of Therapists in Training. Training and Education in Professional Psychology, 1, 105-115. https://doi.org/10.1037/1931-3918.1.2.105

Sheldon, K. M., \& Lyubomirsky, S. (2006). How to Increase and Sustain Positive Emotion: The Effects of Expressing Gratitude and Visualizing Best Possible Selves. The Journal of Positive Psychology, 1, 73-82. https://doi.org/10.1080/17439760500510676

Sin, N. L., \& Lyubomirsky, S. (2009). Enhancing Well-Being and Alleviating Depressive Symptoms with Positive Psychology Interventions: A Practice-Friendly Meta-Analysis. Journal of Clinical Psychology, 65, 467-487. https://doi.org/10.1002/jclp.20593

Skosnik, P. D., Chatterton, R. T., \& Swisher, T., Park, S. (2000). Modulation of Attentional Inhibition by Norepinephrine and Cortisol after Psychological Stress. International Journal of Psychophysiology, 36, 59-68. https://doi.org/10.1016/S0167-8760(99)00100-2

Stalikas, A., \& Lakioti, A. (2012). Satisfaction with Life Scale (SWLS). In A. Stalikas, S. Triliva, \& P. Roussi (Eds.), Psychometric Instruments in Greece (2nd ed., p. 752). Athens: Pedio.

Taris, T., Le Blanc, P., Schaufeli, W. B. \& Schreurs, P. J. G. (2005). Are There Causal Relationships between the Dimensions of the Maslach Burnout Inventory? A Review and Two Longitudinal Tests. Work \& Stress, 19, 238-255.

https://doi.org/10.1080/02678370500270453

Trew, J. L., \& Alden, L. E. (2015). Kindness Reduces Avoidance Goals in Socially Anxious 
E. Alexiou et al.

Individuals. Motivation and Emotion, 39, 892-907.

https://doi.org/10.1007/s11031-015-9499-5

WHO (2006). The World Health Report 2006: Working Together for Health. World Health Organization. https://apps.who.int/iris/handle/10665/43432 